\title{
Developing a Friendly and Productive Language Learning Environment (FPLE) Using the Learner as a Resource
}

\author{
Fred M. Masaazi \\ Correspondence: Fred M. Masaazi, School of Education, College of Education and External Studies, Makerere \\ University Kampala, Uganda
}

Received: June 25, 2015 Accepted: July 8, $2015 \quad$ Online Published: July 23, 2015

doi:10.11114/jets.v3i5.967

URL: http://dx.doi.org/10.11114/jets.v3i5.967

\begin{abstract}
This article addresses the need to develop a friendly and productive Language learning environment (FPLE) using the learners as a resource in schools in Uganda. This is in light of the persistent challenging reality that the teaching and learning of languages in schools appears to be still largely traditional, teacher-centered and examination-oriented, thus not as learner friendly and productive as the case should be. A teacher-centered approach alienates the learner from the instructional process and this affects their levels of attainment and performance. As a result, performance in languages in Uganda is not as good as it should be. The article gives an introduction, explores the nature, characteristics and functions of language, outlines the aims of learning Language and language skills, theoretical review, examines the context of a productive language learning environment, with focus on the roles of the teacher and learner as resource persons, and lastly presents the psychological, sociological and educational advantages of a productive language learning environment.
\end{abstract}

Keywords: contextualized, environment, friendly learning, productive, Uganda

\section{Introduction}

The national education policy in Uganda as presented in the Government White Paper on the Education Policy Review Commission Report (Government of Uganda, 1992) acknowledges the key role education plays in achieving moral, intellectual, ideological, cultural and social development. The direction given by this education policy aims at producing capable and morally upright citizens equipped with adequate and relevant knowledge, correct attitudes towards life and society both at local and national levels, and multiple practical skills (MPS). This can only be achieved if learners are taught in a contextualized friendly and productive environment that caters for their cognitive, affective and psychomotor needs, and obviously using learner - centered interactive methods, activities and materials (Abrahams, 2005). This should apply to all subjects in general and languages in particular. There is also need for a favourable working environment in schools with an ideal productive environment with all the required methods, materials and facilities in place (Government of Uganda, 1992; Government of Uganda, 2010; Lubega, 2005).

Uganda is a developing multilingual country (see map) with an estimated population of 30.7 million (Government of Uganda, 2010: 197) using over 30 languages (Byakutaaga, 2000). Almost all these languages are not developed or taught in schools, and many cannot even be used as medium of instruction. It is mainly English, Kiswahili and the five Ugandan languages: Luganda, Luo, Runyakitara, Ateso and Lugbara that are taught and used as medium of instruction in schools (Government of Uganda, 1992). But even then, the teaching and learning of all these languages still leaves much to be desired (Lubega, 2005; Fisher, 2000; McGregor, 2000; Kagaba, 2000; Sanyu, 2000; Ssebbunga, 2000; Ssebbunga, 2001). Therefore there is need to improve the teaching and learning of languages through the creation of the FPLE.

The Multi-lingual nature of Uganda is shown in the Ethno-Linguistic map (Figure 1) indicating the four major classification of Ugandan Languages. Each classification comprises of several languages / dialects. 


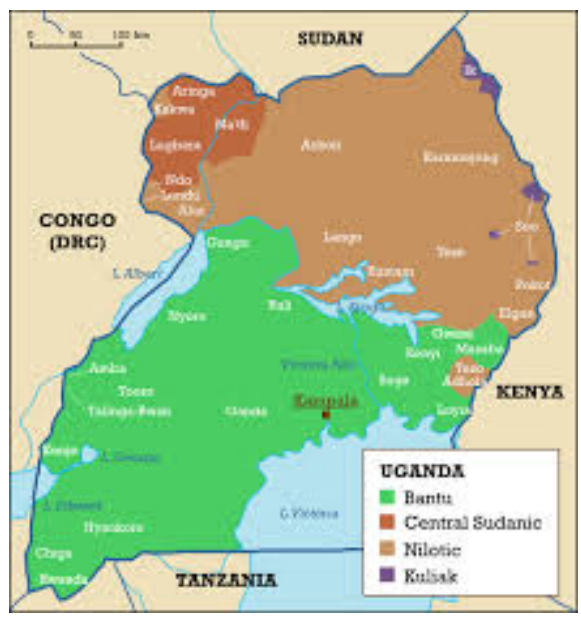

Figure 1. Ethno-linguistic Map of Uganda showing major Language Classifications

Retrieved from https://en.wikipedia.org/wiki/Uganda

\section{Approach and Article Organisation}

Developing an article with emphasis to classroom practice required personal experience with language teaching/learning exposure, extensive observation of the practical reality engagement of the teacher, the learner and the environment. Generally, this choice rendered this article to shift towards an ethnographic design in a qualitative approach which aimed at understanding of a teaching/learning environment phenomenon to support the use of the learner as a major resource. A proponent of this type of design (Kirk et al, 1986, Rossman et al, 1998) draws from a natural setting as a basis of understanding the reality which has not been manipulated before (Kyeyune, 1996). The other aspect which proved worth in compiling this article is the documentary analysis mainly analyzing the Uganda's Education System documents specifically on areas concerning the Language debate.

The documentary analysis was a backbone of this article since the author's understanding of the Uganda's language situation in the larger context of the Uganda's education system pointed to several gaps in the teaching and learning context of languages and thus, the need to address the gaps through proposing the FPLE using the learner as a resource.

This article basically focuses on three major broad areas namely; the general over view of language, the theoretical review and the context of FPLE (methods of teaching, learning materials, role of the learner, and the advantages of FPLE.

\section{The Nature of Language, Characteristics and Functions of Language}

\subsection{Nature of Language}

Language, simply defined is a means of communication. Byakutaaga (2000) says 'language is a means of communication, vocally produced and arbitrary'. Richards et al (1993) agree that language is 'the system of human communication which consists of structured arrangement of sounds or their written representation'. In addition, Crystal (1992) has a similar view that language is 'the systematic conventional use of sounds signs or written symbols in a human society for communication and self expression'. Language is a practical and social subject in nature, thus its learning requires a contextualized, practical and learner centered environment, which appears to be still lacking in schools in Uganda.

Jones (1983) further explains and illustrates that language is a complicated phenomenon with many aspects or dimensions, of which learners and teachers must be aware to be able to handle it adequately and efficiently. According to Jones (1983), these aspects or dimensions are as paraphrased below:

1. Language is a categorizing system. Words are labels given to different features and concepts abstracted from the universal environment.

2. Language is a tool of communication, social interaction and thought in society.

3. Language in this perspective performs many functions: making inquiries, stating facts, ideas and feelings and arguing about them, judging, persuading, and so on.

4. Language is art. Literature and oratory are the two forms of artistic use of language. Literature appeals to the emotions, presenting the beautiful, the sublime (causing feelings of joy and wonder), the pathetic 
(causing feelings of pity and sorrow), and the ridiculous (portraying folly and causing disrespectful laughter). Oratory is the art of public speaking, with the goal of persuading the audience.

5. Language is a system of symbols. Language is a systematic organization of intermeshed sub-systems functioning at several levels from concepts to sound and graphic or written symbols.

6. Language is a set of skills. These skills are speaking, listening, reading and writing. They are special abilities required for effective communication and are developed and mastered through practice.

\subsection{Characteristics and Functions of Language}

The implications of all the above definitions and illustrations are that language primarily serves social communication purposes and thus should be taught and learnt from contextualized and practical perspective. Therefore the most appropriate and productive methods of teaching and learning language are the learner - centered and task - based methods.

Language has many characteristics according to Byakutaaga (2000). It is human behaviour, because it is used only by human beings, it is a structured system with each language having a peculiar way of forming meaningful utterances from words, phrases and sentences, it is arbitrary whereby the sounds, words and patterns used do not have direct relationships with meaning and it is basically vocal or spoken. Language is also a set of symbols, a form of social behaviour and a means of social interaction. Most of these characteristics of language imply that it should be taught from a contextualized and practical learner - centered perspective.

Language serves many functions in education and in society as well. These also have bearing on how it should be taught and learnt. According to Richards et al (1993), language serves descriptive, expressive and social functions, all of which are practical and contextual. According to the Answers.com website, language serves as 'a means of conveying information, it an instrument of action, a means of maintaining social relationships, a marker of groups of people and an instrument of cognitive and conceptual development'. (http://wiki.answers.com/Q/What_are_the_functions_of_language)

The implications of the above characteristics and functions of language are that learners need to learn language in the appropriate context which promotes a practical, learner - centered, friendly and productive environment. According to the Government of Uganda (2004), to succeed the learners in Uganda:

1. to succeed in the workplace, young people will need the ability to follow written directions, understand abstract concepts, go beyond the basics of reading, writing, mathematics and problem solving

2. many will need the ability to use computers at the basic level, enterprises in every sector will require employees who know how to solve problems using rigorous methods of problem identification, hypothesis formulation, data collection and analysis and the ability to reason beyond repetitions of mechanical operation

3. to communicate clearly in writing, think critically and make informed and competent judgments (p.10).

Language should be learnt in a contextualized, practical and productive way to realize the needs expressed above.

\subsection{Aims of Learning Language and Language Skills}

The aims of learning various languages in schools are usually the similar.

This article draws on the specific aims of learning English language in secondary education for illustration. As stated by the Government of Uganda (2008: x), the aims of learning English emphasize are as presented below:

1. To enable learners master the language skills of speaking, listening, reading and writing.

2. To assist learners to develop the ability to understand with reasonable ease rapid speech in situations such as classroom discussions, radio and television programmes, recorded plays, full length films and everyday speech.

3. To enable learners express themselves intelligently, appropriately and effectively in speech.

4. To cultivate in the learners the desire to read by themselves and for their own satisfaction.

5. To encourage the learners to develop the ability to read a wide variety of written materials for enjoyment, information and knowledge.

6. To stimulate students' response to the art of language as used in prose and poetry, as a means of inspiring creativity, and to assist them articulate their responses intelligently.

7. To guide learners in developing their ability to write correctly, creatively and effectively.

The above aims can best be realized when the learning process is conducted in a friendly and productive environment with the learner at the center of the entire process. 


\subsection{Speaking and Listening Sub-skills}

According to the Government of Uganda (2008), learners are expected to train and develop the following speaking and listening sub - skills:

1. Ability to recognize points of articulation.

2. Ability to recognize manner of articulation.

3. Ability to produce sounds and sound combinations peculiar to English: pure vowels, diphthongs and consonants which include plosives, affricates, fricatives, plosives, nasals and laterals.

4. Ability to listen consciously.

5. Ability to speak interestingly: developing the art of conversation, appropriateness of speech, audibility, articulation, voice quality, use of figurative language, practice of features of spoken language such as question tags, the grammar of speech, stress, rhythm, and intonation.

These sub - skills can best be attained when the learning process is conducted in a friendly and productive environment with the learner at the center of the process.

\subsection{Reading Sub-skill}

According to the Government of Uganda (2008), learners are expected to train in the following reading sub - skills to be able to read effectively:

1. Improving reading speed from 120 to 400 words per minute.

2. Improving reading habits: discouraging voicing, movement of the head, lips fingers and bad postures, while encouraging rapid eye movement.

3. Adjusting reading speeds to appropriate materials and purpose.

4. Inferring meanings of unfamiliar words and expressions from context

5. Perception of deeper contextual meaning

6. Responding to and proper use of figurative language

7. Perception of the effect of punctuation on meaning

8. Identifying character traits

9. Assessing group character

10. Relating reading experience to real practical life

11. Distinguishing facts from opinions

12. Judging opinions

13. Grasping themes, ideas and the writer's purpose

14. Tracing and analyzing plot and sequence

15. Articulating the impact of a work on the reader

16. Utilizing reference materials such as the dictionary, atlas, encyclopedia and directories

These sub skills can also best be attained when the learning process is conducted in a friendly and productive environment with the learner at the center of the process.

\subsection{Writing Sub-skill}

According to the Government of Uganda (2008), learners are expected to train in the following writing sub - skills to be able to produce good creative and functional texts:

1. Ability to determine the message and purpose for writing

2. Ability to vividly and appropriately describe concrete objects and situations, abstract ideas and concept sensations.

3. Ability to order in time and place, credible incidents and events

4. Ability to sustain a plot - coherence

5. Ability to sustain tense sequence

6. Ability to develop incidents to a climax 
7. Ability to exploit both plain and figurative language for effective narration

8. Ability to employ punctuation and paragraph structure

9. Ability to project character through direct description, speech and action

10. Ability to make character develop - grow, change and mature

11. Ability to create effective character interaction

12. Ability to handle the language and mechanics of dialogue

13. Ability to handle the essential features of discussion: introduction, definitions, logical statements, stating facts, comparing and contrasting, explanation and illustration of points, giving and evaluating evidence and drawing conclusions.

14. Ability to summarize, take and make notes

All these are practical sub - skills which can best be attained when the learning process is conducted in a friendly and productive environment with the learner at the center of the process. It is important to note that all the above language skills overlap and are leant concurrently, thus can best be learnt and mastered using learner centered interactive methods, notably the Integrated Approach recommended and adopted by the National Curriculum Development Center in Uganda (Government of Uganda, 2008; Ihemere, 2010).

\subsection{The Context of Productive Language Learning Environment}

As already stated, language as a subject is sociological practical in nature, thus can best be learnt in an ideal context. The context should be characterized by a conducive learner - centered and productive environment. It should be noted that "learning environments are typically constructivist in nature, engaging learners in "sense-making" or reasoning about extensive resource sets. Learning environments typically include four components: an enabling context, resources, a set of tools, and scaffolds as explained by Hannafin et al, (1999). Usually, 'authentic or realistic contexts are provided to motivate learners, and typically take the form of complex, full-scale problems representative of real-world tasks. To help students understand their complex problems, extensive resources can be provided. A truly open-ended learning environment would involve students in independent research to find and select their own relevant resources. In some learning environments, however, selected resource sets are provided to learners. A full set of tools should be provided to help the learners to process information, manipulate data, and discuss the data. Scaffolds should also be present to bolster student problem solving as needed. These can take many forms from tools to teachers to student peers' (Hannafin et al, 1999).

An effective and productive enriched learning environment is developed by focusing on four dimensions of the environment:

1. Focus on meaning - meaningful learning, growth in performance, and creating processes/products that make a difference in the world, embedding meaning in the context and artifacts of the environment.

2. Support for each person - align each person with their talents - what they like doing and what they do best, safe environment for taking risks, create alignments with values and interests of individuals, opportunities for professional growth, feedback.

3. Structure for each person - clear performance criteria, scope, schedule, challenge and resources.

4. Collaboration that adds value - Supporting others, using effective practices such as assessment and compelling goals. (From: http://www.webs1.uidaho.edu/ele/Definitions/ele.htm)

All stakeholders in language teaching and learning are supposed to contribute to the creation of an effective and productive learning environment. These include curriculum specialists, teacher trainers and teachers, publishers who produce instructional materials, and examiners.

\section{Theoretical Review}

\subsection{Introduction}

In this section a discussion of the theory used to develop this article is undertaken. The article is guided by the social constructivist theory. Constructivism is a theory based on observation and scientific study about how people learn. The theory is traced from the work of Piaget, Jean (1950) and has developed over time. It has influenced education through recent paradigm shifts in assessment, particularly in America in language arts, science and mathematics, curriculum and teaching and recently in the social studies literature (Scheurman \& Yell 1998). 


\subsection{Social Constructivist Theory}

By the social constructivist theory, students are taught to learn best when involved directly in authentic experiences. The experiences are planned and mediated by the teacher such that students gain in-depth understandings of their own lives within a diverse society and of today's world (Ellis, 2006). A student-centered-constructivist approach incorporates multiple and varied sources of information, and encourage student generated questions to guide inquiry. Language knowledge would be constructed when children are able to form own interpretations of evidence for review (Scheurman 1998). In this way, the application of constructivist theory to language results in the development of deeper understandings of problems and procedures in language and rigorously defensible beliefs about important issues in the discipline. While there are different interpretations of constructivism, the common denominator is a belief that knowledge is created by people and influenced by their values and culture (Phillips 1995)

The cognitive view of constructivism, exemplified by Piaget (1950), posits that, people develop universal forms or structures of knowledge that enable them to experience reality. Knowledge is individually constructed and is based on the knower's intellectual development during physical and social activity. In cognitive constructivism, the teacher's role as a facilitator is to pose problems challenging children's conceptions of reality.

According to Brooks and Brooks (1993) principles of constructivist pedagogy include posing problems of emerging relevance to learners; structuring learning around primary concepts; seeking and valuing children's points of view; adapting curriculum to address student suppositions; and assessing children's learning in the context of teaching. The teacher makes sure he/she understands the students' preexisting conceptions and guides the activity to address them and then build on them.

Social constructivism emphasizes the importance of the learner being actively involved in the learning process, unlike previous educational viewpoints where the responsibility rested with the instructor to teach and where the learner played a passive receptive role. Sustaining motivation to learn is strongly dependent on the learner's confidence in his or her potential for learning (Glasersfeld, 1989). According to Vygotsky (1978) learners are challenged within close proximity to, yet slightly above, their current levels of development and by experiencing successful completion of challenging tasks, learners gain confidence and motivation to embark on more complex challenges. As a matter of pedagogy, learners are constantly challenged with tasks that refer to skills and knowledge just beyond current level of mastery. This captures their motivation and builds on previous successes to enhance learners' confidence. As a matter of approach, instructors have to adapt to the role of facilitators and not teachers. Whereas a teacher gives a lecture that covers the subject matter, a facilitator helps the learner to get to his or her own understanding of the content. While in the former approach the learner plays a passive role, in the latter approach, the learner plays an active role in the learning process. The emphasis turns away from the instructor and the content, towards the learner (Gamoran, Secada, \& Marrett, 1998). This change of role implies that a facilitator needs to display a totally different set of skills than a teacher. A teacher tells, a facilitator asks; a teacher lectures from the front, a facilitator supports from the back; a teacher gives answers according to a set curriculum, a facilitator provides guidelines and creates the environment for the learner to arrive at his or her own conclusions; a teacher mostly gives a monologue, a facilitator is in continuous dialogue with the learners. A facilitator adapts the learning experience by taking the initiative to steer the learning experience to where the learners want to create value.

The learning environment is designed to support and challenge the learner's thinking. The critical goal is to support the learner in becoming an effective thinker (Kim 2005)

\section{Use of Appropriate Methods of Teaching}

\section{1definition of Teaching}

Teaching, according to Farrant (1985) is 'a process that facilitates learning'. This is through the creation or provision of a conducive and productive environment for effective learning to take place. Nsubuga (2000) says that teaching 'may be regarded as providing opportunities for pupils to learn. It is an interactive activity as well as an intentional one.' Matiru, et al (1995) also explains that 'method refers to the modus operandi of teaching or the way information is transmitted to the learner. Methods describe conceptually the instructional process, that is, not only how information gets from teacher to learner but also how the learner uses it, interacts with it, receives guidance, and is given feedback'. Learners thus should in ideal circumstances be at the center of the instructional process and should contribute much during learning.

\subsection{Methods of Language Teaching}

The methods of teaching used in language learning determine the roles and levels of involvement of learners. There are two broad categories of methods according to Matiru et al (1995) teacher - centered and learner - centered methods. Teacher centered methods relate to the old psychological theory of tabula rasa (http://en.wikipedia.org/wiki/Tabula_rasa) based on the premise that 'individuals are more or less a homogenous group born without in - built mental content and 
that their knowledge comes from experience and perception'. The role of the teacher is to impart knowledge to the learner and the position of the learner is more of that of a passive recipient. The recent learner - centered methods are based on the premise that learners have in - built potential and have individual differences in terms of intelligence, personality and learning ability thus are heterogeneous. The differences between the teacher and learner - centered methods are illustrated in table 1 :

Table 1. Comparison of Teacher and Learner - centered Methods

\begin{tabular}{lll}
\hline Areas of focus & Teacher-centered methods & Learner-centered methods \\
\hline Approach & Expository, talk and chalk & Discovery, dialogue and inquiry \\
Purpose & Transfer of information & Development of individual potential \\
Rationale & Education as technology & Education as a liberating process \\
Strategy & Surface learning & Deep learning \\
Teaching link & Direct & Indirect \\
Teacher role & Authority, all knowing expert & Facilitate, helper, developer \\
Teacher activity & Telling, checking correcting & Guiding the learners \\
Student role & Role learning & Self-direction for meaning \\
Student activity & Listening, note taking & Exploring, reflecting, questioning \\
\hline
\end{tabular}

Source: Matiru et al (1995: 116)

A comparison of teacher and learner - centered methods in table 1 show that teacher - centered methods do not give learners the best context for language learning. Teacher - centered methods like lecture, drills and chalk and talk or exposition limit learners' practical development of skills and negatively affect the language learning process. Learner centered methods such as class discussions, demonstrations and problem solving on the other hand give learners an ideal interactive context for language learning.

The nature of language and aims of teaching language explained above have implications for methods of teaching, materials and activities. Language by virtue of its practical and sociological nature requires learner - centered interactive methodology. Ssebbunga (2000) proposes content - based instruction. He says:

'Content based instruction is grounded in the widely accepted claim that language is best learned if it is used as a medium to discuss and teach the content of interest and relevance to the learners... By definition, content based instruction refers to the integration of content with language teaching aims...the concurrent study of language and subject matter...'

In content - based instruction, language is taught in the context and needs of the learners, with focus on practical use. This can help create a productive language learning environment.

Lubega (2005) observes that 'many learners in Uganda finish primary school without knowing how to read and write effectively; some even reach university level without any significant improvement in their literacy skills'. This is due to use of teacher centered methods. She proposes use of the break through to literacy (BTL) interactive methodology, experimented by Kyambogo University to help create a conducive, productive and practical learning environment that equips learners for life.

Richards et al (2007) explain other related learner - centered teaching methods including communicative language teaching (pp 153 - 177), the natural approach (pp 178 - 190), cooperative language learning (pp 192 - 201), content based instruction (pp $204-220$ ) and task based language teaching (pp 223 - 241). All these methods are learner centered and can help empower the learners. In addition, the National Curriculum Development Center (2008) has adopted the Integrated Approach to language teaching, which also emphasizes learner centered, interactive, practical and contextualized language instruction.

\section{Use of Appropriate Learning Materials}

Instructional materials are very important in creating a conducive, practical and productive learning environment. According to Nkuuhe (1995), 'in educational psychology, students learn by receiving information through the sense organs such as the ears, eyes, nose, mouth and tongue, hands and skin. From experience, there is a relationship between the quantity of information we remember and the sense organs being used'. In addition, students learn skills, concepts and ideas better when they try them out in practice. The old adage that 'practice makes perfect' has a sound educational basis. A clear illustration of these ideas is Edgar Dale's cone of learning (from: 
http://wikiclassroomtud.wikispaces.com/Cone+of+learning), whereby learners remember $10 \%$ of what they read in books, $20 \%$ of what they hear from the teacher in lessons, $30 \%$ of what they see in teaching aids, $50 \%$ of what they see and hear in demonstrations, exhibits or the field, $70 \%$ of what they say in discussions, debates or presentations and $90 \%$ of what they say and do practically on their own.

Instructional materials have important advantages according to Nkuuhe (1995), because they:

1. Allow easy and repeated reproduction of an events or learning procedures

2. Provide visual access to a process or technique

3. Provide a common framework of experience to a large number of learners

4. Promote an illusion of reality

5. Gain and hold the attention of the learner

6. Focus attention or highlight key points

7. Save time by avoiding wordy explanations

8. Create lasting impact

9. Facilitate the understanding of abstract concepts

There is need for appropriate and adequate instructional to help create an ideal productive language learning environment. These include print, static display, visual, audio - visual and electronic materials. The materials help support learning practice and also provide a clear and specific cultural context for learning.

\section{The Role of the Learners}

Learners should play a central role during the language learning process, under the guidance of the teacher. They should not just study to pass examinations but rather look at the language class work as an integral part of their individual academic growth and development of skills and values. The learners ideally and in summary should be at the center of the learning process; therefore, they should be able to perform the following;

i. Actively participate in all learning activities. ii. Be critical, analyze new ideas and contrast them with what they know. iii. Fully interact, ask and answer questions. iv. Be creative and produce learning materials. v. Be well motivated, thus care about what they are learning. vi. Incorporate new knowledge into daily life activities, and other courses. vii. Interacts freely with the teacher and other students. viii. Question own beliefs and practices. ix. Be open minded, free and always willing to learn more. x. Be proactive and responsible for their own learning. xi. Be disciplined, respectful and tolerant of new ideas and information. xii. Be willing to work hard and make full use of class time. xiii. Be very serious, curious, aware and focused in their mission. xiv. Always relate and apply what they are learning in real life

Learners have many roles to play during the instructional process in the learner -centered language classroom. The teacher plays many roles as a facilitator: planning by drawing schemes of work, lesson plans and developing or selecting learning materials, guiding the learners through the lesson activities, imparting new ideas to the learners, helping learners acquire and practice new skills, assessing learners' progress, guiding and counseling learners with academic and behaviour related problems, researching to improve on the knowledge and keep up to date and organizing extra curricular activities.

Advantages from a friendly and productive language learning environment, there are many advantages learners can get from a friendly and productive language learning environment, these are as presented below.

\subsection{Psychological Advantages}

There are many psychological advantages arising from a friendly and productive language learning environment. In the first case, such an environment is good and challenging thus helps in developing the learners' cognitive skills. They are challenged to think and use the language. The environment is also good for developing learners' affective skills, as they use the language and react to different situations and challenges. It can also help motivate the learners and the teachers because such an environment makes the learning lively and interesting. The learning environment also helps in building the learners' confidence and sense of independence as they handle the tasks and use language on their own, without depending on the teacher. Lastly, it makes the teachers' work easier, lively and interesting and by doing so reduces risks of psychological stress. 


\subsection{Sociological Advantages}

In addition to the psychological advantages presented above, there are also many sociological advantages arising from a friendly and productive language learning environment. In the first case the learners practice and develop psychomotor communication skill which they can use in real life in society. The learners also develop social skills as they interact both in class and in extra curricular activities, and by doing so; they learn appropriate language behaviour in society. The ideal environment also helps the learners identify, tap and develop their natural language related skills or talents. The learning environment also helps in building the learners' confidence and sense of security as they overcome fear of using language in public as handle the tasks and use language on their own in front of their classes. Lastly, it helps in building a positive rapport between the teachers and learners as they interact freely in class.

\section{Educational Advantages}

Lastly, in addition to the psychological and sociological advantages presented above, there are also many educational advantages associated with a friendly and productive language learning environment. In the first instance, the learners have much more chances of retention or remembering and applying the language skills and structures learnt. This is because of the practical and meaningful nature of language learning in such an environment as was illustrated with Dales' cone of learning cited above.

The productive learning environment provides much direct or immediate feedback for the teacher. This helps in correcting learners directly and reducing the burden of marking piles of errors and mistakes. There is much more learner involvement in the instructional process. The learners own the instructional process and by doing so learn far much faster and more effectively. This is due to the fact that they are at the center of the instructional process practically using the language in simulated real life situations, identifying and addressing their mistakes as a class. The environment can help in production of materials for language learning by the class. This is through practical tasks from which both the good and poor pieces of work can be used for learning instead of relying only on text books and other original material prepared by language specialists.

The illustration in Figure 2 portrays the advantages accruing from the use of FPLE as discussed in the earlier sections. Each variable (psychological, Sociological and Educational) in the figure influences the outcome of each.

\section{LEARNING ENVIRONMENT}

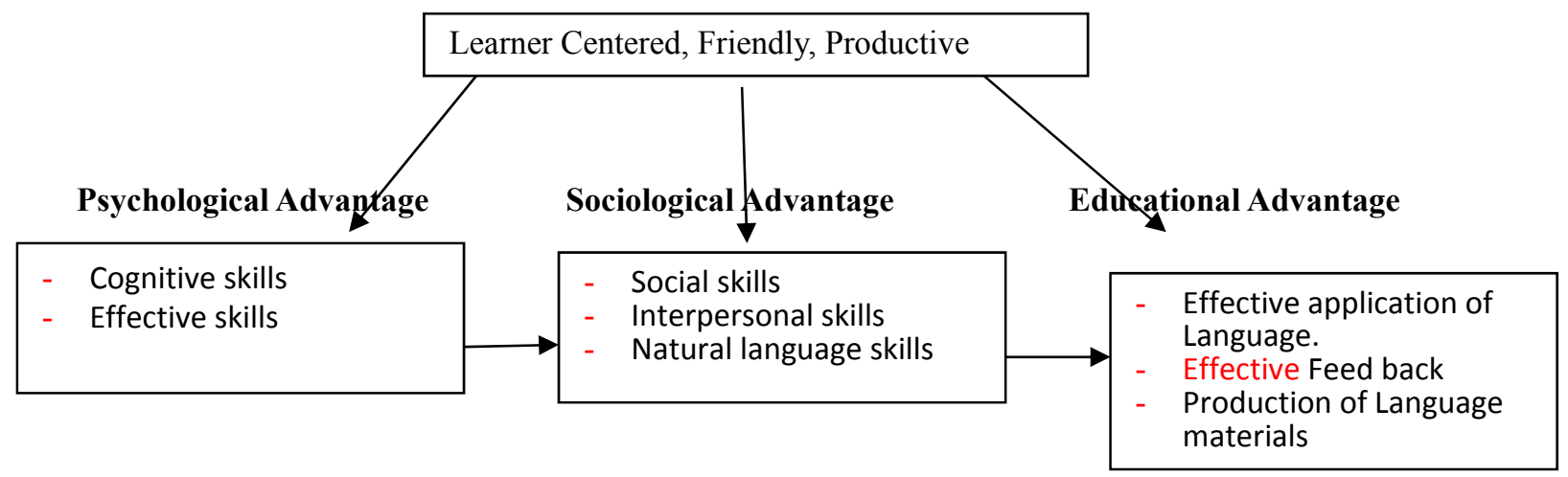

Figure 2. Diagrammatic representation of FPLE Advantages.

\section{Discussion and Conclusion}

The foregoing sections of this article, point to the usefulness of the teachers to be mindful of environment in which they are teaching from. Accessing and preparing a conducive environment does not only impact on the learning outcomes but also helps the teacher to fulfill his/her teaching aims and objectives as confirmed by Masaazi (2004). A teacher should also devote the same effort to the learner's characteristics which impacts heavily to the learning process. A learner contributes to the environment in one way or another and thus his characteristics which may include and not limited to the level of the learner proficiency, the status of the language (mother-tongue or second language).

Its also observed that the development of FPLE using the learner empowers the learner since he/she is a direct beneficiary and contributes to the building of the learning process because learning has commenced from what the learner know or from the known to unknown. In other words, the learner's experiences play a big role in the identification of the content (Canale et al, 1980). It should also be noted that the teaching learning exercise here, become a shared task which is interesting to both the learner and the teacher. A strong and well designed friendly relationship between the two players the learner rand the teacher saves time and contributes greatly to the masterly of 
the language (Phillips, 1995).

Since the teaching and learning environment has become friendly and productive, the emotional, psychological and social intellect of the learner is energized to handle all types of communication and related challenges (Labov, 1971).

During teaching, the teacher should have the ability to develop a culture of sharing experiences (Hannafin, et al, 1999), between the two parties i.e. the learner and the teacher. Sharing through a friendly learning environment contributes to confidence building (Glasersfeld, 1989) which is a requisite to continuous language proficiency. For these developments to bear fruits in FPLE there is a requirement of the type and selection of teaching /learning materials. Therefore, a teacher should look for environmentally, culturally friendly materials which promotes the learner to learn new language aspect. Taking into consideration that Uganda is a multi-lingual country a lot of creativity and innovation on the part of the teacher in selecting the teaching/learning materials to enforce the FPLE is paramount.

In conclusion therefore, it's categorically clear that, there is need to develop a friendly and productive language learning environment using the learners as a resource in schools in Uganda. This can help improve learners' levels of attainment and performance in languages in the country. Benchmarking from Language Learning environment, improvement in other learning areas will automatically occur. Therefore, teachers are advised to work towards setting a conducive learning environment which will help the learner to achieve maximum outputs from the teaching learning exercise. In doing this the learner characteristics, appropriate methodology, learner's level of language proficiency, the classroom environment, the aims of teaching and learning language, requires prioritization in preparing the language lesson

\section{References}

Abrahams, L. (2005). What is Interactive Teaching? http://wiki.answers.com/Q/What_are_the_functions_of_language

Brooks, J., \& Brooks, M. G. (1993). In Search of Understanding: The Case for Constructivist Classrooms. Alexandria, VA: Association for Supervision and Curriculum Development.

Brooks, J., \& Brooks, M.G. (1993). In Search of Understanding: The Case for Constructivist Classrooms. Alexandria, VA: Association for Supervision and Curriculum Development.

Bruner, J. S. (1972). The Process of Education Revisited. Cambridge. Massuchets: Havard University Press.

Byataaga, C. S. (2000). An Introduction to the Study of Language. Kampala: Makerere University: Department of Distance Education

Canale, M., \& Swam, M. (1980). Theoretical Basis of Communicative Approaches to Language Teaching and Learning.

Crystal, D. (1992). The Cambridge Encyclopaedia of Language. Cambridge: Cambridge University Press Enriched learning environments at http://www.webs 1.uidaho.edu/ele/Definitions/ele.htm

Ellis, A. K. (2006). Teaching and learning Elementary Social Studies (8th Ed.) Boston: Ellyn and Bacon.

Farrant J. S. (1985). Principles and Practices of Education, Essex: Longman.

Fisher, P. (2000). English in Uganda: of standards and standards, in Parry, K. Language and Literacy in Uganda. Fountain Publishers.

Gamoran, A., Secada, W.G., Marrett, C.A (1998). The organizational context of teaching and learning: changing theoretical perspectives, in Hallinan, M.T (Eds), Handbook of Sociology of Education

Glasersfeld, E. (1989). Cognition, construction of knowledge, and teaching. Synthese, 80(1), 121-124. http://dx.doi.org/10.1007/BF00869951

Government of Uganda (1992). White Paper on the Education Policy Review Commission Report Entitled Education for National Integration and Development. Kampala; Ministry of Education and Sports.

Government of Uganda (1999). Uganda Primary School Curriculum, Volume 1. Kampala: National Curriculum Development Center.

Government of Uganda (2003). The Achievements of Primary School Pupils in Uganda in English Literacy and Numeracy. Kampala: Uganda National Examinations Board.

Government of Uganda (2004). Education Sector Strategic Plan (ESSP, 2004-2005). Kampala: Ministry of Education and Sports.

Government of Uganda (2008). Integrated English Teaching Syllabus (Uganda Certificate of Education). Kampala: National Curriculum Development Center.

Government of Uganda (2010). National Development Plan (2010/ 11 - 2015/2015). Kampala: Ministry of Education and Sports. 
Hannafin, M., Land, S., \& Oliver, K. (1999). Open learning environments: foundations, methods and models. http://www.edtech.vt.edu/edtech/id/models/environs.html

Ihemere, K. U. (2010). An Integrated Approach to the Study of Language Attitudes and Change in Nigeria: The Case of the Ikwerre of Port Harcourt City. University of Newcastle upon Tyne, United Kingdom. http://www.lingref.com/cpp/acal/36/paper1424.pdf

Jones, B. (1983). Developing Language skills. Kampala, (Unpublished Manual). Department of Language Education, Makerere University.

Kagaba, P. (2000).Progress in promoting Kiswahili in Ugandan schools, in Parry, K. Language and Literacy in Uganda. Fountain Publishers.

Kim (2005). The Effects of a Constructivist Teaching Approach on Student Academic Achievement, Self-Concept, and Learning Strategies. Asia Pacific Education Review, 6(1), 7-19. http://dx.doi.org/10.1007/BF03024963

Kirk, J., \& miller, M. L. (1986). Reliability and VLIDITY IN Qualitative Research. Beverly Hills: Sage Publications.

Kyeyune, R. (1999). Ethnography. Kampala.

Labov, W. (1972). Sociolinguistic Patterns. Philadelphia; University of Pennsylvania Press, Oxford: Blackwells

Lubega, M. (2005). Interactive methodologies: BTL in operation in Uganda, in Parry, K. Teaching Reading in African Schools. Kampala: Fountain Publishers.

Masaazi, F. M. (2004). Prospects and Challenges of Improving the Teaching of Luganda through the Integrated Functional Approach. (Unpublished Doctoral Thesis) Makerere University, Kampala, Uganda.

Matiru, B., Mwangi, A., \& Schlatte, R. (1995) (ed) Teach Your Best. Kassel: University of Kassel.

McGregor, G. P. (2000). National policy and practice in language and literature education: some reflections from afar, in Parry, K. Language and Literacy in Uganda. Kampala: Fountain Publishers.

Nkuuhe, J. (1995). Instructional media, in Matiru, B. et al Teach Your Best. Kassel: University of Kassel.

Nsubuga, E. H. K. (2000). The Teacher as a Professional. Kampala: MK Publishers.

Phillips, D. (1995). The Good, the Bad, and the Ugly: The Many Faces of Constructivism. Educational Researcher, 24(7). http://dx.doi.org/10.3102/0013189X024007005

Piaget, J. (1950). The Psychology of Intelligence. New York: Routledge.

Richards, J. C., \& Rodgers, T. S. (2007). Approaches and Methods in Language Teaching. Cambridge: Cambridge University Press

Rossman, G. B., \& Rallis, S. F. (1998). Learning in the Field: An Introduction to Qualitative Research. Throsnd Oaks, Ca Sage publication.

Sanyu, F. (2000). Difficulties of teaching in the mother tongue, in Parry, K. Language and Literacy in Uganda. Fountain Publishers.

Scheurman, G., \& M. Yell (Eds.). Constructing Knowledge in Social Studies. Theme Issue. Social Education, 62.

Ssebbunga, C. M. (2000). Content - based language teaching: a commendable approach in Makerere English Language and Literature Teaching Journal, 1(1).

Ssebbunga, C. M. (2001). The State of the use, teaching and learning of English Language in Uganda's Education System, in Uganda Education Journal, 3.

UNESCO (2010). World Data on Education. 7th Edition at http://www.ibe.unesco.org/pdf

Vygotskii, L. S. (1978). Mind in society: The development of higher mental processes. Cambridge, MA: Harvard University Press, In Vygotsky's philosophy: Constructivism and its criticisms examined Liu \& Matthews, International Education Journal, 2005, 6(3), 386-399.

Wikipedia Encyclopaedia Cone of learning at http://wikiclassroomtud.wikispaces.com/Cone+of+learning downloaded on $3^{\text {rd }}$ June 2011

Wikipedia Encyclopedia Theory of tabula rasa at http://en.wikipedia.org/wiki/Tabula_rasa

\section{(cc) Br}

This work is licensed under a Creative Commons Attribution 3.0 License. 